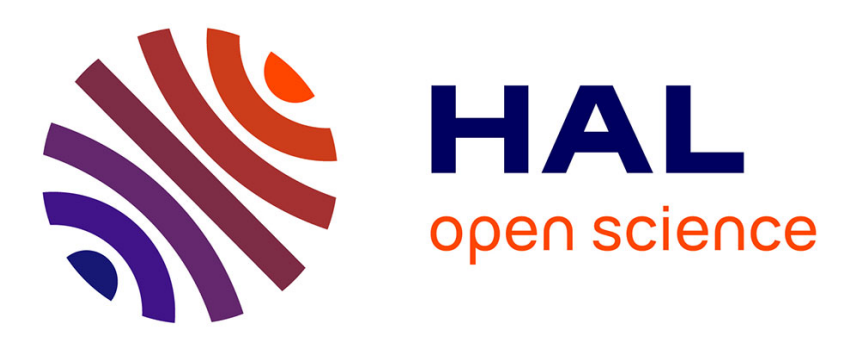

\title{
The effect of connectives on the selection of arguments: Implicit consequentiality bias for the connective "but"
}

François Rigalleau, Michèle Guerry, Lionel Granjon

\section{To cite this version:}

François Rigalleau, Michèle Guerry, Lionel Granjon. The effect of connectives on the selection of arguments: Implicit consequentiality bias for the connective "but". Journal of Psycholinguistic Research, 2014, 43 (4), pp.465-485. 10.1007/s10936-013-9265-3 . hal-01341811

\section{HAL Id: hal-01341811 \\ https://hal.science/hal-01341811}

Submitted on 4 Jul 2016

HAL is a multi-disciplinary open access archive for the deposit and dissemination of scientific research documents, whether they are published or not. The documents may come from teaching and research institutions in France or abroad, or from public or private research centers.
L'archive ouverte pluridisciplinaire HAL, est destinée au dépôt et à la diffusion de documents scientifiques de niveau recherche, publiés ou non, émanant des établissements d'enseignement et de recherche français ou étrangers, des laboratoires publics ou privés. 


\section{Journal of Psycholinguistic Research}

The effect of connectives on the selection of arguments: Implicit consequentiality bias for the connective "but"

--Manuscript Draft--

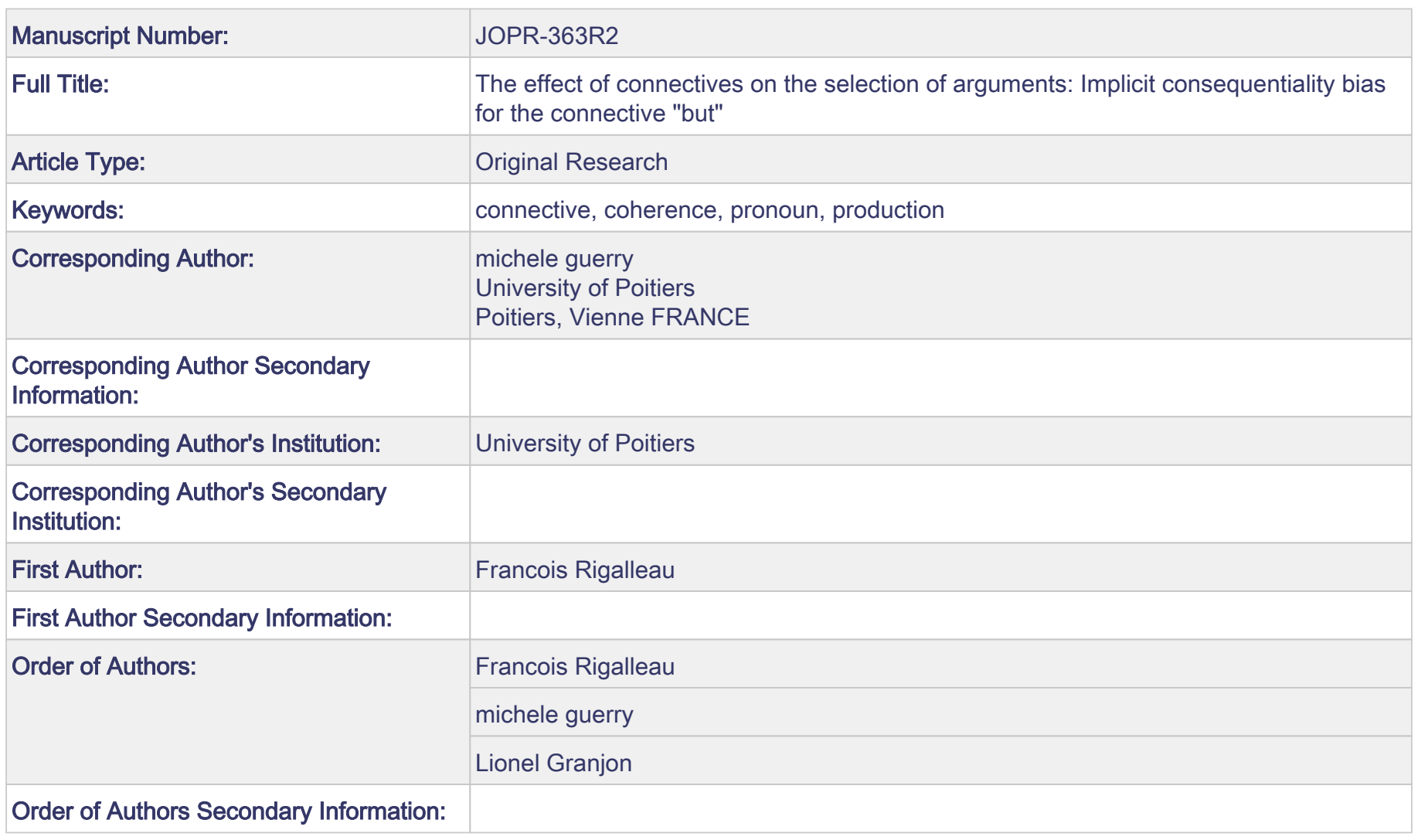


Response to Reviewer Comments

\section{Responses to reviewer 1 :}

1/ The paragraph on page 3

it was replaced by the suggestion of Rev1.

2/ The last paragraph of the paper

it was replaced by the suggestion of Rev1.

3/ Examples of verbs

Rev1 advised us to quote a few examples of verbs every time we use the denomination Stimulus-Experiencer, Experiencer-Stimulus, or Agent-Evocator, since the reader must keep going back to the examples in order to follow the discussion.

The ms was quite long, so we decided to give only 1 example at each mention of the categories (Unless this resulted in giving an example twice in 3 sucessive sentences).

For SE : frighten, for ES : fear, for AE : congratulate

4/ awkward sentences and typos

all were corrected as suggested by Rev 1

Thank you for all the constructive comments, they improved the ms (note that we thank Rev1 in the author note) 
The effect of connectives on the selection of arguments: Implicit consequentiality bias for the connective "but"

François Rigalleau

Centre de Recherches sur la Cognition et l'Apprentissage (CERCA),

CNRS UMR 7295

Université de Poitiers

Michèle Guerry

Centre de Recherches sur la Cognition et l'Apprentissage (CERCA),

CNRS UMR 7295

Université de Poitiers

Lionel Granjon

Grenoble Images Parole Signal Automatique (GIPSA) Laboratoire

CNRS UMR 5216

Université de Grenoble

Address correspondence to:

François Rigalleau

Laboratoire CERCA,

CNRS, UMR 7295

5 rue Theodore Lefebvre,

F-86000 POITIERS, France

Tel: +33549454610

Fax: +33 549454616

e-mail: francois.rigalleau@univ-poitiers.fr 


\begin{abstract}
$\underline{\text { Abstract }}$
Recent studies about the implicit causality of inter-personal verbs showed a symmetric implicit consequentiality bias for psychological verbs. This symmetry is less clear for action verbs because the verbs assigning the implicit cause to the object argument (e.g. "Peter protected John because he was in danger.") tend to assign the implicit consequence to the same argument (e.g. "Peter protected John so he was not hurt."). We replicated this result by comparing continuations of inter-personal events followed by a causal connective "because" or a consequence connective "so". Moreover, we found similar results when the consequence connective was replaced by a contrastive connective "but". This result was confirmed in a second experiment where the time required to imagine a consistent continuation for a fragment finishing with "but s/he ...". The results were consistent with a contrastive connective introducing a denial of a consequence of the previous event. The results were consistent with a model suggesting that thematic roles and connectives can predict preferred co-reference relations.
\end{abstract}




\section{$\underline{\text { Introduction }}$}

Since Garvey and Caramazza (1974), it is assumed that some interpersonal verbs have an implicit causality bias because one of their arguments is more easily taken as involved in the cause of the event denoted by the verb. For instance, Garvey and Caramazza (1974) showed that a verb like "to admire" has a causal bias in favor of its object argument. In a fragment like (1), participants prefer to continue the fragment by assigning the referent "Bill" to the pronoun. Because "Bill" is the second noun phrase, this type of verb is also called "NP2 biasing verb". Other verbs like "to disappoint" show the reversed causal bias: they are called "NP1 biasing verbs", as in (2).

(1) John admired Bill because he ...

(2) John disappointed Bill because he ...

Many verbs showing an implicit causality bias denote psychological events because one of the arguments feels an emotion. This argument receives a thematic role called "Experiencer". The other argument is sometimes called the "Stimulus" (e.g., McKoon, Greene, \& Ratcliff, 1993). For these psychological verbs, Brown and Fish (1983) noted that the implicit causality bias is in favor of the Stimulus. Stevenson, Crawley and Kleinman (1994) replaced the causal connective "because" by the connective "so" which introduces a consequence. They found a reversed bias concerning the attribution of a referent to the ambiguous pronoun. Stewart, Pickering and Sanford (1998) reported a similar consequentiality bias in favor of the Experiencer using different contexts (e.g. "Because John admired Bill, ...").

This inversion of the reference bias suggested to Crinean and Garnham (2006) that the role of Stimulus is associated with the cause of the mental verb event, and that the Experiencer role is associated with the immediate consequences of the same event. These authors suggested there was a direct mapping between semantic roles and cause/consequence.

However, concerning action verbs, the relation between roles and biases seems more complex. According to Crinean and Garnham (2006) the Agent is normally associated with the cause of the 
event, and the Patient is related to the consequence. However, some action verbs (e.g., praise, punish) seem to have an implicit causality bias in favor of their Patient. To explain this apparent discrepancy, Crinean and Garnham noticed that these verbs (e.g., "congratulate," "thank") form a specific class called "Agent-Evocator" verbs by Rudolph and Försterling (1997). The subject of the verb is an Agent, however the verb describes an interaction where the activity of the Agent is mainly in reaction to a state or behavior of the Patient. The Patient seems to evoke the reaction of the Agent. According to Crinean and Garham, such verbs possess both an action component and a psychological component because their Agent is reacting to a property or an attitude of the other character. For those verbs, the implicit cause and the implicit consequence are assigned by attributing the second argument either an Evocator or a Patient role. The implicit cause is assigned by considering the psychological component. In this case, the verb is assumed to have an Agent-Evocator structure and therefore the implicit causality is more naturally assigned to the Evocator rather than to the Agent. However, the implicit consequence is assigned relative to their action component. In this case, the second character (interpreted as a Patient), would be used as support for the explicitation of a consequence. It must be clear that the global effect is that the same character would be preferred to refer both to cause and to consequence.

The relation between semantic roles (sometimes called thematic roles) and consequentiality bias seems robust in the model proposed by Crinean and Garnham. The consequence is associated with the Patient or with the Experiencer. In our paper, we make use of this relation to examine the existence of a referent bias for the contrastive connective "but". Lakoff (1971) suggested that "but" tends to introduce a violation of expectation, when this contrastive connective follows a clause with the form "NP1 verbed NP2." If expectations evoked by the verb mainly concern the consequences of the event denoted by the verb, then a consequence bias should emerge for the connective "but".

The contrastive connective "but" 
Frege (1892) noticed that "but" shares some important properties with the coordinate conjunction "and". At a logical level, it seems that the truth conditions of a contrastive connective are similar to those of "and": the entire sentence is true if each clause is true. For instance, the connective "but", as "and", cannot be used if the two connected clauses are contradictory, as in (3).

(3) *Peter hates John but Peter does not hate John.

However, "and" and "but" are different because a felicitous use of "but" requires additional constraints on the semantic relation between the clauses and/or on the context.

Lakoff (1971) distinguished two uses of "but": the "semantic opposition" and the "denial of expectation". According to Lakoff, when "but" is used to mark a semantic opposition, as in (4), the coherence of the two clauses is allowed without requiring any kind of world knowledge or contextual factors. The use of two antonym expressions (e.g., "quick" vs. "slow" ; "hate" vs. "like") constitutes the base of the semantic opposition. As illustrated by both examples, this type of "but" is generally associated with different grammatical subjects mentioned in the two related clauses, avoiding a simple contradiction as in (4). In this condition, using antonym predicates does not result in a simple contradiction. On the other hand, if the two clauses have subjects referring to the same entity, the semantic opposition would result in an inacceptable sentence, as illustrated in (5).

(4) John is quick but Bill is slow.

(5) *John is quick but John is slow.

When the two clauses refer to the same entity, "but" frequently introduces a clause where the predicate is not in strict semantic opposition with the previous clause, as in (6).

(6) John is tall but he's no good at basketball. 
Lakoff proposed that (6) is an instance of "but" marking a "denial of expectation" (see also Kehler, 2002). The coherence is allowed by an expectation made possible by the first clause: "someone who is tall is good at basketball". The contrastive connective "but" is possible in (6) because it signals that the second clause mentions information which is not consistent with the expectation as illustrated in (7) and (8)

(7) John is tall, so he is good at basketball.

(8) John is tall, but he is not good at basketball.

Both "but" and "so" can introduce clauses making reference to plausible expectations based on the content of the first clause and on world knowledge, although "but" implies a violation of such expectations. Because expectations tend to concern the consequences of an event, we could expect that both connectives "so" and "but" will provoke a preference for referring to the character associated with the consequential part of the event in the first clause, following Crinean and Garnham, this character is the Patient, or the Experiencer. Grober, Beardsley and Caramazza (1978) explicitly compared the contrastive "but" with the causal connective "because" in a continuation task. They used verbs with implicit causality biases, but they inserted various modal auxiliaries in front of the verbs (e.g., "John should scold Bill because he ..."). Two verbs had a strong causality bias in favor of the subject ("apologize" and "accuse"), three other verbs had a causal bias in favor of the object ("criticize", "praise", and "scold"). Grober et al. compared the pronominal assignment when "because" was replaced by "but". For all the verbs, they found a bias in favor of the grammatical subject when the connective "but" was used. This result is apparently in contradiction with our prediction. However, two aspects of their study should be noticed. First, the authors asked participants to complete each sentence, writing a reason or a motive that was appropriate for the action presented in the first part of the sentence. This instruction could induce consistent continuations with "because" than 
with "but." Second, Grober et al. reported that, with the connective "but," participants "simply generated an explicit denial of the action with the pronoun referring to the grammatical subject of the main clause" (Grober et al., 1978, p. 125). This result seems surprising because, as we noted earlier, "but" cannot felicitously combine two contradictory clauses.

\section{The present study}

In the two experiments here reported, we used contexts with implicit causality verbs showing an implicit causality bias either in favor of the NP1 or in favor of the NP2. Half of the verbs were action verbs assigning the Agent role to NP1 and Patient role to NP2. The other half were psychological verbs: these verbs assign an Experiencer role to one NP and a Stimulus role to the other NP. In the first experiment here reported, we used the classical paper and pencil continuation task. This experiment compared the continuation results for three connectives: the causal connective "because," the consequence connective "so," and the contrastive connective "but." It was designed to check whether the consequence connective and the contrastive connective would result in similar patterns of continuations. In Experiment 2, we used an on-line production paradigm (Guerry, Gimenes, Caplan, \& Rigalleau, 2006) to evaluate the planning time required to imagine a consistent continuation when the contrastive connective "but" was followed by a pronoun referring either to NP1 or to NP2. In this experiment, we also tested the following predictions. First, continuations referring to the Patient or to the Experiencer of the initial clause would elicit more references to consequences in their predicates than continuations referring to the Agent or to the Stimulus. Second, the predicates referring to consequences would take the form of denials of plausible consequences.

\section{Experiment 1}

The first experiment was paper-and-pencil continuation study designed to test two main hypotheses. Contrary to Grober et al. (1978), we decided to not ask participants to write a reason 
or a motive consistent with the fragment. The instructions only asked for a consistent continuation. Three connectives were compared: "because" used in a pre-test phase to select verbs; "so" and "but" used in the test phase with the verbs selected during the pre-test phase. The first hypothesis was that action verbs with a causal bias in favor of their object also present a consequence bias in favor of the same argument, as predicted by Crinean and Garnham (2006). In other words, Agent-Evocator verbs (e.g., to congratulate) should show similar biases in favor of NP2, with the causal connective "because" and with the consequence connective "so." On the other hand, the NP1 biasing verbs and the psychological NP2 biasing verbs should show reversed biases when the causal connective is replaced by a consequence connective. The second hypothesis was that contrastive connective "but" should show the same bias as consequence connective "so".

\section{$\underline{\text { Materials }}$}

Thirty-two verbs with an implicit causality bias were used to construct the experimental materials. Sixteen verbs had a bias in favor of their grammatical subject (NP1 biasing verbs), and sixteen verbs had a bias in favor of their grammatical object (NP2 biasing verbs). For NP1 biasing verbs, 8 verbs described events where the subject NP was an agent, and the object NP was a patient . The other 8 NP1 biasing verbs described events where the subject NP was a Stimulus, and the object NP was an Experiencer. For NP2 biasing verbs, 8 verbs described events where the subject NP was an Agent, and the object NP was a Patient. The other 8 NP2 biasing verbs had a subject NP which was an Experiencer, and an object NP which was a Stimulus. The 32 verbs are given in Appendix 1. The properties of the verbs were evaluated in three different tasks. A continuation task was used to evaluate the causal bias. A Role judgment task allowed checking the thematic roles assigned by the verbs. Finally, a Reactor judgment task was used to check whether action verbs with a causal bias in favor of NP2, like "to congratulate", called AgentEvocator verbs by Crinean and Garnham (2006), were specifically associated with NP1 reacting to a behavior of NP2. 
The existence and the strength of the causal bias were checked in a pilot continuation experiment involving two groups of 27 subjects and 96 verbs. Each verb was inserted in a fragment of the form "NP1 verb-ed NP2 because ..." where NP1 and NP2 had different genders. For each fragment, the participants had to imagine a consistent ending mentioning one of the NPs. For each verb, twenty-seven participants wrote a continuation. The results allowed the selection of 32 verbs with same mean amplitude of causality bias for the four sets of 8 verbs. The first column of Table 1 reports the percentages of participants who referred to the relevant NP for the four types of verbs.

Table 1 here

The assignment of the role to each NP was checked in an independent study with 28 different participants. Each verb was presented in a sentence with two different gender first names. (e.g., "Thérèse a mécontenté Richard." [Teresa displeased Richard.]). For the 16 verbs denoting an activity, the participants had to underline the character who accomplished an action (i.e., the Agent) for one half of the verbs, and the character who experienced or received an action (i.e., the Patient) for the other half of the verbs. For the 16 verbs denoting a psychological state, the participants had to underline the character who experienced a feeling (i.e., the Experiencer) for one half of the verbs, and they had to underline the character who created the experience of a feeling (i.e., the Stimulus). The verbs contained in each half were counterbalanced across participants with the constraint that each half contained as many NP1 biasing verbs and NP2 biasing verbs. The results of this pre-evaluation are reported in the two middle columns of Table 1. For all verbs, the role assignments were in the expected direction, with a minimum of $82.5 \%$ assignment for the expected Stimulus or Agent. 
Finally, we evaluated the hypothesis formulated by Crinean and Garnham (2006) about the specific status of the NP1 for action verbs with an NP2 bias. We conducted a third paper and pencil study. Participants were presented the sentences used to test the roles assigned by the Agent-Patient verbs. For each sentence they had to decide to what degree the subject character acted in reaction to a certain state of the object character. A scale from 0 to 4 was used to note their evaluation for each verb. Twenty students from the University of Poitiers participated in this study. They did not participate in other experiments here reported. The hypothesis was that the score should be higher for NP2 biasing action verbs than for NP1 biasing action verbs. The results are reported in the final column of Table 1. As predicted by Crinean and Garnham, the mean score was greater for NP2 biasing action verbs than for NP1 action biasing verbs ( $\mathrm{t} 1(19)=$ $8.06, \mathrm{p}<.01 ; \mathrm{t} 2(14)=3.53, \mathrm{p}<.01)$. This result confirmed that NP2 biasing action verbs are specifically associated with an Agent reacting to a property of the Patient.

The final four sets of 8 verbs were used to construct fragments with two first names differing in gender. Different pairs of first names were used for each fragment. A first version of a fragment had as a final word the connective "so", the second version had the connective "but", as in (9) and (10).

(9) Bernard a influencé Martine donc ...

Masc. ${ }^{1}$ influenced Fem. so ...

(10) Bernard a influencé Martine mais ...

Masc. influenced Fem. but ...

Each fragment was written on a different page of a booklet with a different random order of sentences for each booklet. The instructions asked participants to continue the fragment with a consistent clause containing a reference to one of the names in the fragment. 


\section{Subjects and Design}

There were three variables: the Type of Verb (Action vs. Psychological); the Causal bias of the verb (NP1 causal bias vs. NP2 causal bias) ; and Connectives ("so" vs. "but").

Two groups of 27 students participated in this Experiment. The first group read booklets where all the fragments had "so" as a final connective, the second group read booklets where all the sentences had "but" as a final connective. This design offered the opportunity to compare the results obtained with connective "because" for the same verbs during the selection step of the material construction.

\section{$\underline{\text { Results }}$}

Two independent raters examined the predicates on the 2592 (i.e. 864 continuations for each connective) continuations to see whether they were consistent with the main clauses. Three scores could be assigned to a predicate: $1=$ only consistent with the subject of the clause; 2 = could be consistent with both the selected subject and the alternative referent; $3=$ only consistent with the alternative referent. The initial independent ratings disagreed on only 91 continuations (3.5\%). All initial disagreements were resolved by discussion. A total of $20(0.7 \%)$ continuations received score 3 . The score 2 was assigned to 150 continuations $(5.8 \%)$. Thus the great majority of continuations were consistent with the fragment.

Because NP1 continuations and NP2 continuations were complementary, the analyses were carried out on NP1 continuations. Table 2 reports the percentages of NP1 continuations for each connective.

\section{Table 2 here}


These data were analyzed in two analyses of variance (ANOVAs). The first ANOVA used subjects as a random factor $\left(\mathrm{F}_{1}\right)$ and involved two within-subject factors: The Type of Verb (Action vs. Psychological), and Verbal causal bias (NP1 biasing verb vs. NP2 biasing verb); the Connective factor ("because" vs. "so" vs. "but") was a between subjects factor. The second ANOVA used verbs as a random factor $\left(\mathrm{F}_{2}\right)$ : it involved the same factors, but Type of Verbs and Verbal Causal bias were between items factors, and Connective was a within-item factor.

There was a three-way interaction $\left(\mathrm{F}_{1}(2,78)=16.1, \mathrm{p}<.01 ; \mathrm{F}_{2}(2,56)=6.1, \mathrm{p}<.01\right)$. For the verbs with a causal bias in favor of NP1, the two-way interaction between Type of Verbs and Connectives was not significant $(\mathrm{F} 1(2,78)=0.4 ; \mathrm{F} 2(2,28)=0.14)$. The effect of Type of Verb was not significant (both Fs $<1)$. The effect of Connectives was significant $(\mathrm{F} 1(2,78)=190.7$, $\mathrm{p}<.01 ; \mathrm{F} 2(2,28)=108, \mathrm{p}<.01)$. Planned comparisons revealed that there was a significant difference between Connectives "but" and "so" by subjects $(\mathrm{F} 1(1,78)=4.6, \mathrm{p}<.05 ; \mathrm{F} 2(1,28)=$ 2.6, $\mathrm{p}>.1$ ), suggesting more NP1 continuations with "but" than with "so". However the contrasts comparing the connective "because" with both the other connectives were significant both by subjects and items $(\mathrm{F} 1(1,78)=376.7, \mathrm{p}<.01 ; \mathrm{F} 2(1,28)=214.5, \mathrm{p}<.01)$ : NP1 continuations were more frequent for the connective "because". Considering verbs with a causal bias in favor of NP2, the two-way interaction between Type of Verb and Connectives was significant $\left(\mathrm{F}_{1}(2,78)=26.5\right.$, $\mathrm{p}<.01 ; \mathrm{F} 2(2,28)=8.9, \mathrm{p}<.01)$. For psychological verbs with NP2 causal bias, the effect of Connectives was significant $\left(\mathrm{F}_{1}(2,78)=50.8, \mathrm{p}<.01 ; \mathrm{F}_{2}(2,14)=12.2, \mathrm{p}<.01\right)$. Planned comparisons revealed that "so" and "but" did not differ significantly $\left(\mathrm{F}_{1}(1,78)=0.2 ; \mathrm{F}_{2}(1,14)=\right.$ 0.4). However, the causal connective "because" induced less NP1 continuations than the two other connectives $\left(\mathrm{F}_{1}(1,78)=101.5, \mathrm{p}<.01 ; \mathrm{F}_{2}(1,14)=24.4, \mathrm{p}<.01\right)$. Finally, for action verbs with NP2 causal bias, the effect of Connectives was not significant $(\mathrm{F} 1(2,78)=2.4, \mathrm{p}>.09$; F2 $(2,14)=1.82, \mathrm{p}>.05)$

We conducted t-tests to compare the percentages of NP1 continuations relative to a chance performance (subjects would randomly write NP1 continuations or NP2 continuations after a fragment). The random performance was $50 \%$. There were $26 \mathrm{df}$ in the analysis by subjects and 7 
df in the analysis by items. Table 2 reports the $t$ values. For the connective "because," the NP1 continuations were more frequent than chance both for Agent-Patient verbs and for StimulusExperiencer verbs (e.g., frighten), the NP1 continuations were less frequent than chance both for Agent-Evocator verbs (e.g., congratulate) and for Experiencer-Stimulus verbs (e.g., fear). For the connective "so," and the connective "but" the NP1 continuations were less frequent than chance for Agent-Patient verbs, for Stimulus-Experiencer verbs, and for Agent-Evocator verbs. However, the percentage of NP1 continuations was not significantly different from chance for ExperiencerStimulus. This analysis confirmed that the pattern of preferred reference was similar for "so" and for "but." However, for Experiencer-Stimulus verbs, even if references to the Experiencer were more frequent than for "because", these references did not become significantly more frequent than chance.

The hypothesis was that connectives "so" and "but" should activate the implicit consequentiality bias of verbs, eliciting similar NP biases for both connectives. There should be a reliable correlation between the NP biases for the consequence connective "so" and for the contrastive connective "but". This correlation was computed across the 32 verbs, taking NP1 percentages as measured variable. The correlation was significant $(\mathrm{r}(30)=0.67, \mathrm{p}<.01)$.

\section{$\underline{\text { Discussion }}$}

This experiment confirmed our main hypothesis concerning the differential bias for "because", so" and "but". The connectives "but" and "so" did not differ, but they both changed the causal bias observed for NP1 verbs and for psychological NP2 verbs. For Agent-Evocator NP2 verbs, the causal bias in favor of NP2 remained with both "so" and "but." We partly confirmed the hypothesis proposed by Crinean and Garnham concerning connective "so," because this connective elicited more references to the Experiencer than the causal connective "because." However, this trend resulted in Experiencer references more frequent than chance only for Stimulus-Experiencer verbs (e.g., frighten). We generalized their claim to the contrastive connective "but" which induced more frequent references to the Experiencer for psychological 
verbs, and more frequent references to the Patient for Action verbs. This aspect of our results was only partly consistent with results reported by Grober et al. (1978) because these authors reported a general trend to favor NP1 continuations when the contrastive connective was used. These authors used a different design and a different instruction to get their continuation data.

\section{Experiment 2}

Experiment 1 showed that when an interpersonal clause is followed by a contrastive connective, participants preferred to write a continuation referring to the Patient or to the Experiencer in the previous clause. We suggested that this preference is related to a tendency to refer to the consequence of the event. According to Lakoff (1971), the contrastive connective is associated with a partial rejection of a plausible expectation evoked by the initial clause. If expectations activated by an interpersonal event primarily concern the Patient or the Experiencer, then computing a contrastive continuation about a Patient or an Experiencer should be easier than computing a contrastive continuation about an Agent or a Stimulus. In Experiment 2, we used an on-line methodology (Guerry et al., 2006) to measure the time required to plan a predicate consistent with a pronoun referring either to the first name or to the second name. Our main hypothesis was that participants would take more time to imagine a consistent continuation when the pronoun refers either to the Agent or to the Stimulus in the main clause than when it refers to the Patient or to the Experiencer. We were also interested in the content of the continuations. If the Patient and Experiencer roles are more strongly associated with the potential consequence of the main event, then participants should make more references to consequences when the pronoun refers to the Patient or the Experiencer than when it refers to the Agent or to the Stimulus. Finally, following Lakoff's theory, we predicted that the continuations referring to consequences should deny a plausible expectation.

In Experiment 2, the participants read the first clause of a sentence. This first clause finished with a contrastive connective. The two nouns of this first clause had different genders, and they were 
the subject and the object of a NP1 biasing verb or of a NP2 biasing verb. After this segment, a pronoun agreeing with one of the two nouns was presented to the participant. At this point, the task was to imagine a consistent ending for the clause starting with this pronoun. When this ending was found by the participant, s/he wrote it on paper. This paradigm enabled the time to imagine a continuation when this continuation must be consistent with either the first NP or the second NP of the first clause to be measured.

\section{$\underline{\text { Materials }}$}

The verbal materials were similar to those used in Experiment 1. However, we added a pronoun referring to either NP1 or NP2 at the end of each sequence, presented separately, as indicated in $(11-12)$.

For each of the verbs, two versions of a sentence were constructed. Sentences (11-12) illustrate the two versions. The slash indicates the limit between the two segments that were successively presented to the participants. Two first names with different genders, but with identical number of letters, were associated with one version; for this version the pronoun referred to the first NP. In the second version, a different pair of first names was used, although the number of letters in each first name was maintained; for this second version, the pronoun referred to the second NP.

\section{Version with a pronoun referring to NP1}

(11) Bernard a influencé Martine mais / il Masc. influenced Fem. but / he

Version with a pronoun referring to NP2

(12) Etienne a influencé Josiane mais / elle Masc. influenced Fem. but / she 
A second list was constructed by systematically reversing the order of the two first names in the clauses, as in (13-14). This inversion allowed controlling potential effects of gender on the strength of the contrastive bias.

(13) Martine a influencé Bernard mais / il

Fem. influenced Masc. but / he

(14) Josiane a influencé Etienne mais / elle

Fem. influenced Masc. but / she

Twelve filler items were also constructed. These items were constituted with one verb and two same gender first names (6 items with two female first names, and 6 items with two male first names). The causal connective was replaced by "et" ("and") for these items. The pronoun was plural as illustrated in (15).

\section{(15) Patrice a couru avec Anthony et / ils Peter ran with Anthony and / they}

Each of the four lists of 64 experimental items was mixed with the same 12 filler items. For each list, five pseudo-randomized orders were established avoiding that the same verb occurs in two successive items.

Four training items were also constructed: three had the experimental connective (i.e., "but"), and one had the filler connective (i.e., "and").

Participants were tested individually in a quiet room. Successive stimuli were presented in black characters (Times New Roman 20-point bold characters) in the center of a PC computer screen with a white background. The participant used a graphic digitalizing tablet Wacom SC- 
$421 \mathrm{E}$ to trigger the appearance of stimuli, and to write the continuation. Figure 1 illustrates the different zones of this tablet.

Figure 1 here

To start a trial, the participant put the lead of the pen on a departure square which was outside the active zone of the tablet. The experimenter pressed a button which activated two events: the appearance of the fragment (e.g. "John annoyed Ann but") on the screen, the measurement of what will be called the "reading time" of this fragment. Once the participant had read this fragment, s/he moved the lead of the pen onto a second square on the right (distance from the departure square $=15 \mathrm{~mm}$ ). This second square was on the part of the graphic digitalizing tablet where presses of the pen were recorded. When the lead pressed this second square, four events occurred: the fragment disappeared on the screen, it was replaced by a pronoun (e.g. "he"), the internal clock of the computer finished the measure of the reading time, the internal clock started the measurement of what will be called the "planning time" of the continuation. The participant had to imagine a continuation, and was instructed to raise the pen from the square when s/he was sure of the continuation $\mathrm{s} / \mathrm{he}$ wanted to write. The raising of the pen activated two events: the pronoun disappeared from the screen, and the internal clock finished the measurement of the "planning time". Finally, the participant wrote the continuation on the graphic digitalizing tablet where all the movements and pauses of the pen were recorded. To finish the trial, the participant pressed an "End" square at the bottom of the tablet. After this, the pen was posed on the departure square of the next line to start the next trial. As can be seen on Figure 1, there were six trials on each sheet of paper. The experimenter changed the sheet when the participant finished the six trials. 
The planning times (as the others writing times) were collected using the software GStudio (Chesnet, D., Guillabert, F., \& Esperet, E., 1994).

\section{Subjects and design}

Twenty subjects participated in this experiment. They were students of the University of Poitiers. None of them participated in the previous experiments.

There were two variables in the design: the causality bias of the verb in the main clause (NP1 biasing verb vs. NP2 biasing verb); and the referent of the pronoun (NP1 vs. NP2). Each participant saw each verb with a pronoun referring to NP1 and with a pronoun referring to NP2, although different names were used in the two cases.

\section{$\underline{\text { Results }}$}

The 1280 continuations written by the participants were examined by two judges to see whether they were consistent with the main clause. Three scores could be assigned to a continuation: $1=$ perfectly consistent with the pronoun; 2 = possible (i.e. could be consistent with pronoun "he" or "she"; 3 = not consistent with the pronoun. Globally, only 62 continuations received score 3 , so $95.1 \%$ of the continuations were consistent with the main clause, suggesting that subjects followed the instruction.

Two times were analyzed: the reading time of the first fragment, and the planning time. The hypotheses concerned the planning time. For these two dependent variables, the same data trimming was carried out. For each participant, the mean time and the standard deviation was computed for each of the four conditions. The times that were greater than 2 standard deviations from the mean were replaced by the maximum time of the subject in the relevant condition. The replacement affected less than $5 \%$ of the data.

These data were analyzed in two analyses of variance (ANOVAs) for each dependant variable. The first ANOVA used subjects as a random factor $(\mathrm{F} 1)$. It involved three within-subject factors: Type of Verb (Action vs. Psychological) ; Verbal bias (NP1 biasing verb vs. NP2 biasing 
verb); Referent of the final pronoun (NP1 vs. NP2). The second ANOVA used items as a random factor (F2): it involved the same factors, but Referent was a within-items factor, Type of verb and Verb bias were between-items factors.

Concerning the mean reading times, the ANOVAs revealed only one significant effect: the main effect of Verbal bias $\left(\mathrm{F}_{1}(1,19)=17.3, \mathrm{p}<.01 ; \mathrm{F}_{2}(1,28)=12.5, \mathrm{p}<.01\right)$. The mean reading time was longer for NP1 biasing verbs $(\underline{\mathrm{M}}=4379 \mathrm{~ms}, \underline{\mathrm{SD}}=1195)$ than for NP2 biasing verbs $(\underline{\mathrm{M}}$ $=3990 \mathrm{~ms}, \underline{\mathrm{SD}}=978)$. A similar effect was reported by Guerry et al. (2006) with similar materials.

Table 3 reports the mean planning times for all the conditions.

Table 3 here

The main effect of Type of verb was significant $(\mathrm{F} 1(1,19)=8.4, \mathrm{p}<.01 ; \mathrm{F} 2(1,28)=6.6, \mathrm{p}<.05)$ with longer planning times after reading mental verb events than after reading action events. The main effect of Referent was significant by items $\left(F_{1}(1,19)=2.9, p>.05 ; F_{2}(1,28)=7.3, p<.05\right)$ suggesting longer times when the pronoun referred to NP1. The main effect of Verbal bias was not significant (both $\left.F_{s}<1\right)$. The three way interaction was significant $(F 1(1,19)=12.2, \mathrm{p}<.01$; $\mathrm{F} 2(1,28)=11.8, \mathrm{p}<.01)$.

For NP1 biasing verbs, the decomposition of this interaction showed that the two-way interaction involving Type of Verbs and Referents was not significant (both Fs $<1$ ). For NP1 biasing verbs, the mean planning time was longer when the pronoun referred to NP1 than when it referred to NP2 $\left(F_{1}(1,19)=6.6, p<.05 ; F_{2}(1,14)=25.8, p<.01\right)$, confirming the inversion relative to the causal bias which favors NP1. On the other hand, for NP2 biasing verbs, the twoway interaction between Type of Verbs and Referents was significant $(\mathrm{F} 1(1,19)=20.2, \mathrm{p}<.01$; $\mathrm{F} 2(1,14)=15.5, \mathrm{p}<.01)$. For the Agent-Evocator verbs (e.g., congratulate), mean planning time 
was longer when the pronoun referred to NP1 than when it referred to NP2 $(F 1(1,19)=7.7$, $\mathrm{p}<.05 ; \mathrm{F} 2(1,7)=5.02, \mathrm{p}<.07)$, indicating a persistence of the bias in favor of NP2 noticed with "because", although the effect was only significant by subjects. For the Experiencer-Stimulus verbs (e.g., fear), mean planning time was longer when the pronoun referred to NP2 $(\mathrm{F} 1(1,19)=$ $6.1, \mathrm{p}<.05 ; \mathrm{F} 2(1,7)=20.7, \mathrm{p}<.01)$, reversing the contrastive bias noticed for NP1 biasing verbs. The effects noticed on planning times could be related to the lengths of the computed continuations. Two ANOVAs were conducted on the number of words in the continuations written by participants. None of the main effects or interaction effects were significant by subjects or by items (all Fs $<1)$. The mean number of words in all the continuations was 5.4 words $(\underline{\mathrm{SD}}=$ 2).

Our hypotheses only concerned the "planning time" - that is the delay before the participant raised the pen to write the continuation. We analyzed the next time recorded on the tablet. This time corresponded to the time between the participant raising the pen from the second square and the following press of the pen on the tablet to write the first word in the continuation. If participants followed the instructions, this time should be short relative to planning times and it should not be affected by the variables manipulated in the experiment. The mean value of this time was $893 \mathrm{~ms}(\underline{\mathrm{SD}}=434.6)$. This value was clearly less than the mean planning-time value $(5,112 \mathrm{~ms})$. We did not find reliable effects of the factors on this time at level .05 by subjects or by items.

\section{$\underline{\text { Content analysis }}$}

\section{Continuations referring to consequences}

Two judges independently analyzed the contents of the continuations. For each continuation, they had to decide whether it referred or not to a potential consequence of the first clause. A continuation was judged as referring to a consequence either when this continuation expressed a potential consequence with an affirmation, as in (16) or when it denied a potential consequence, as in (17). After a first analysis, the two 
judges disagreed for only 38 of the 1280 continuations. The cases under discussion were excluded from the "Consequence" category.

(16) Karine a aidé Thomas mais il s'est trompé.

Fem. helped Masc. but he made a mistake.

(17) Karine a aidé Thomas mais il ne l'a pas remerciée.

Fem. helped Masc. but he did not thank her.

Table 4 reports the mean percentages of continuations referring to potential consequences for each type of verb, and according to the noun referred by the subject pronoun in the continuation.

Table 4 here

Two ANOVAs were computed on the percentages of consequence continuations with the same factors as for the previous ANOVAs on responses times.

The main effect of Type of verb was not significant $\left(\mathrm{F}_{1}(1,19)=3.6, \mathrm{p}>.05 ; \mathrm{F} 2(1,28)=2.9\right.$, $\mathrm{p}>.05)$. The main effect of Verbal bias was not significant $(\mathrm{F} 1(1,19)=1.2, \mathrm{p}>.05 ; \mathrm{F} 2(1,28)=$ 0.7). The main effect of Referent was significant $\left(F_{1}(1,19)=87, p<.01 ; F_{2}(1,28)=33, p<.01\right)$ suggesting more references to consequences when the pronoun referred to NP1. The three way interaction was significant $(\mathrm{F} 1(1,19)=23, \mathrm{p}<.01 ; \mathrm{F} 2(1,28)=15.2, \mathrm{p}<.01)$.

For NP1 biasing verbs, the decomposition of this interaction showed that the two-way interaction involving Type of Verbs and Referents was not significant (both Fs $<1$ ). For NP1 biasing verbs, the percentage of continuation referring to consequences was higher when the pronoun referred to NP2 than when it referred to $\mathrm{NP} 1\left(\mathrm{~F} 1(1,19)=72.8, \mathrm{p}<.01 ; \mathrm{F}_{2}(1,14)=\right.$ 69.2, $\mathrm{p}<.01$ ), confirming that predicates associated with the Patient or the Experiencer referred more to consequences than predicates associated with the Agent or the Stimulus. On the other 
hand, for NP2 biasing verbs, the two-way interaction between Type of Verbs and Referents was significant $\left(\mathrm{F}_{1}(1,19)=57.7, \mathrm{p}<.01 ; \mathrm{F}_{2}(1,14)=40.1, \mathrm{p}<.01\right)$. For the Agent-Evocator verbs (e.g., congratulate), the consequence continuations were more frequent when the pronoun referred to $\mathrm{NP} 2\left(\mathrm{~F} 1(1,19)=23.7, \mathrm{p}<.01 ; \mathrm{F}_{2}(1,7)=22.6, \mathrm{p}<.01\right)$. For the Experiencer-Stimulus verbs, like "to fear", the consequence continuation were more frequent when the pronoun referred to the Experiencer $(\mathrm{F} 1(1,19)=48.8, \mathrm{p}<.01 ; \mathrm{F} 2(1,7)=19, \mathrm{p}<.01)$

The effects noticed on the percentage of consequence continuation were similar to the effects noticed on planning times. When the continuations were easier to compute (lower planning times), the continuations also referred more to potential consequences of the previous event. This analysis confirmed that contrastive continuations referring to the Experiencer or to the Patient (or Evocator) of the previous event tend to refer more frequently to consequences than continuations referring to the Stimulus or to the Agent. A t test was computed by participants and by items to compare the observed percentages to $50 \%$. There were $19 \mathrm{df}$ in the subjects analyses, and $7 \mathrm{df}$ in the items analyses. Table 4 reports the $\mathrm{t}$ value. Four percentages were significantly higher than chance both by subjects and by items: when the pronoun referred to the Patient of Agent-Patient verbs; when the pronoun referred to the Experiencer of Stimulus-Experiencer verbs (e.g., frighten); when the pronoun referred to the Evocator (or Patient) of Agent-Evocator verbs (e.g., congratulate); and when the pronoun referred to the Experiencer of Experiencer-Stimulus verbs (e.g., fear), although this last result was only significant by subjects. On the other hand, when the pronoun referred to the Agent, consequences were less frequent than chance for AgentPatient verbs and for Agent-Evocator verbs, but only by items. Finally, when the pronoun referred to the Stimulus, consequences were less frequent than chance for Stimulus-Experiencer verbs and for Experiencer-Stimulus verbs.

Globally, these analyses confirmed that consequence continuation were more frequent than chance when the pronoun referred to the Patient or to the Experiencer. This is important to notice for Experiencer-Stimulus verbs because it is not obvious that the Experiencer of such verbs is the center of the consequence of an action (i.e., "to fear" could not be taken as an action). 


\title{
$\underline{\text { Denial of expectations }}$
}

Although the previous analysis confirmed that participants preferred to refer to potential consequences when the pronoun referred to the Experiencer or to the Patient, the hypothesis formulated by Lakoff was more precise. Participants should formulate a denial of expectation when "but" is present. Concerning the consequence continuations, this hypothesis suggests that the consequence that was produced should not be the most plausible consequence. To test this hypothesis we conducted two transformations on the consequence continuations. First, when the continuation was formulated in a negative sentence, we removed the syntactic negation, and when it was formulated in an affirmative sentence, we inserted a syntactic negation. Second, the connective "but" was replaced by "so." The examples in Table 5 are taken from the collected data. For each type of verb, two examples are given: the first contained a negative continuation (noticed (a)), the second contained an affirmative continuation (noticed (b)). The examples marked with (a') and (b') are the resulting transformed sentences. The examples illustrate cases where the pronoun referred to the Patient or to the Experiencer.

\section{Table 5 here}

Two independent judges decided if the resulting transformed continuations were plausible continuations. They agreed on all cases. Table 6 reports the percentages of plausible transformed continuations.

Table 6 here

\begin{abstract}
As can be seen in Table 5, the percentages of plausible transformed consequences were higher than $80 \%$ in all conditions. It was not possible to conduct $t$ tests or ANOVAs on these data because some subjects did not formulate consequence continuations (percentages of plausible transformed continuations could
\end{abstract}


not be computed for those subjects). However, $\chi^{2}$ tests were applied on each percentage to compare with chance (i.e., 50\% plausible and 50\% non plausible). The CHI square values are reported in Table 5. All values were highly significant $(\mathrm{p}<.01)$ showing that, in all conditions, the consequence continuations were denials of plausible continuations in the majority of the cases. Second, there seemed to be fewer plausible transformed continuations when the pronoun referred to the Agent or to the Stimulus. Examples are reported in Table 7 to illustrate such cases for each type of verb.

Table 7 here

As can be seen, in such instances, the participants tended to give a plausible consequence when "but" was present. This sort of continuation was felicitous, perhaps because it referred to an unusual event in current life (i.e. "to be punished", "to regret own's words", "to be hurt", "to get angry").

This tendency to formulate fewer denials of plausible consequences when the continuation referred to an Agent or a Stimulus was tested by using a Chi square test comparing percentages of transformed plausible continuations when the pronoun referred to the Patient/Experiencer and when it referred to the Agent.Stimulus. When the test was applied for each type of verb, it was only significant for Agent-Evocator verbs like "to congratulate" $\left(\chi^{2}=5.06, \mathrm{p}<.05\right)$ and for Stimulus-Experiencer verbs like "to frighten" $\left(\chi^{2}=3.59, \mathrm{p}<.06\right)$. In addition, collapsing over all verb types, the test was significant, $\left(\chi^{2}=7.22, \mathrm{p}<.01\right)$

We conclude from these data that the majority of the consequence continuations conformed to the "denial of expectation" hypothesis because they were negations of plausible consequences.

\section{$\underline{\text { Discussion }}$}

Using "but" as connective, Experiment 2 showed that the time required to imagine a continuation was shorter when the pronoun referred to the Patient or to the Experiencer than when it referred to the Agent or to the Stimulus of the main event. This experiment confirmed the existence of a bias in favour of the 
Patient or the Experiencer when participants had to imagine a continuation starting with "but" and suggests that this bias was due to the fact that such continuations were easier to compute. The content analyses revealed that the majority of the continuations referring to the Patient or to the Experiencer referred to potential consequences of the previous event. Such consequence continuations were less frequent when the pronoun referred to the Agent or to the Stimulus. This result is consistent with the view suggesting a relation between thematic roles and consequences (Crinean and Garnham, 2006). Consistent with Lakoff's hypothesis, the content analyses also showed that consequence continuations following the contrastive connective "but" were mainly denials of plausible consequences.

\section{$\underline{\text { General Discussion }}$}

Concerning the implicit causal bias, Experiment 1 confirmed the hypotheses proposed by Crinean and Garnham (2006). The cause is assigned more frequently to the Stimulus than to the Experiencer. It is also more frequently assigned to the Agent than to the Patient, unless the verb assigns a Reactor status to the Agent (and an Evocator role to the Patient), as for action verbs with an implicit causal bias in favor of NP2. We reported empirical data confirming that those specific verbs are judged as assigning a Reactor status more frequently than verbs assigning the implicit cause to an Agent subject (see the pre-test section of Experiment 1).

However, the main contribution of our experiments concerned the implicit consequential bias. Consistent with Crinean and Garham's hypothesis, Experiment 1 reported continuation data suggesting a direct mapping between "classical" thematic roles and consequence. When the connective "so" introduced a final clause, the participants preferred to mention the Patient or the Experiencer as the grammatical subject of this clause. According to Crinean and Garnham, this bias reflects an association between these roles and the consequences of the event. Patients and Experiencers undergo the action or the process denoted by the verb, so they might be thought of part of the consequences of the action or the process. 
The two experiments reported empirical evidence suggesting that this bias in favor of the Patient or the Experiencer could be also observed with contrastive connectives like "but". This connective induced more continuations referring to the Patient or to the Experiencer than continuations referring to the Agent or to the Stimulus (Experiment 1). Moreover, Experiment 2 showed that participants took more time to imagine a contrastive continuation when its grammatical subject referred to the Agent or to the Stimulus than when it referred to the Patient or to the Experiencer. The relation between those roles and the consequence was confirmed in a content analysis. Participants referred more frequently to consequences when the grammatical subject was the Patient or the Experiencer of the previous event than when it was the Agent or the Stimulus. Of course, these results do not imply that participants use the same continuations when "so" or "but" is present. A second content analysis revealed that the majority of the consequence continuations in Experiment 2 were denials of plausible consequences. This result was consistent with Lakoff's hypothesis concerning the contrastive connective: it can be used to introduce a denial of expectation. For the contexts used in these experiments, the most available expectations activated by the verbs concerned the consequences when the contrastive clause had a Patient or an Experiencer as grammatical subject.

If our results are consistent with Crinean and Garnham (2006), we would like to note that the notion of thematic role used by these authors is currently discussed in linguistics (e.g. Levin and Rappaport-Hovav, 2005). The specific label of a thematic role is often difficult to specify, and a possible hierarchy of thematic roles is also difficult to establish. Although the roles ascribed to our verbs were confirmed by subjective ratings collected before the experiment, it remains possible that the roles are determined by more basic syntactic or semantic properties of the verbs. In an alternative approach of the semantic-syntax interface, Dowty (1991) suggested that Stimulus-Experiencer (e.g., frighten) verbs and transitive Action verbs share the property of assigning to their object the property of undergoing a change of state, generally caused by the grammatical subject. Under this view, the Experiencer-Stimulus verbs (e.g., fear) constitute a specific class where none of the arguments are assumed to undergo such change of state (i.e., 
"Peter feared Mary" can be understood as describing a state). A possible generalization would be to say that consequences are generally associated with the argument undergoing a change of state. This proposal is interesting because it would be consistent with some aspects of the results concerning Experiencer-Stimulus verbs, like "to fear". In Experiment 1, the consequential bias in favor of the Experiencer NP1 was weak for these verbs (56\% with "so", and 54,2\% with "but"). It could indicate that the lack of a clear change of state for these verbs impeded the assignment of a consequence to a specific character. If this approach is certainly possible to explain consequentiality bias, it remains to be refined concerning the causality bias. For instance Dowty's approach would assign the cause of a change of state to the Stimulus of StimulusExperiencer verbs like "to frighten" (cf. Dowty, 1991, p.580). It could also assign a causal feature to the Stimulus of Experiencer-Stimulus verbs, like "to fear", because it is assumed to be a cause of the state in the Experiencer (cf. Dowty, 1991, p. 579). However, it remains to be clarified whether this approach could distinguish Agent-Patient verbs (e.g., to phone) and Agent-Evocator verbs (e.g., to congratulate) in term of causal bias. Pickering and Majid (2007, p.785) noticed that Dowty's approach does not recognize an Evocator role and suggested that this criteria to define this role was unclear. As noticed in the Material section of Experiment 1, the rating of participants about the Evocator feature for all our action verbs confirmed that Agent-Patient and Agent-Evocator verbs could be distinguished by non-linguist raters. This could be taken as an argument in favor of Crinean and Garnham's view. It remains to establish if this Evocator role could be related to more primitive semantic or syntactic properties of verbs, or is only related to properties associated with social or cultural features of real-life situations.

The results of this study supported the view that thematic roles are related to the expectations that parsers have about causality and consequentiality when two actions and/or events are connected by subordination. Thus, the thematic structure of a predicate, combined with the connectives used between clauses, is an important determinant of the co-reference relations between clauses (Crinean \& Garnham, 2006). Our experiments extend this view by considering a contrastive connective ("but"). Thematic roles seem to propose default candidates for potential 
continuations. In general, there is a preference for consequentiality being related to the patient or the Experiencer in Agent-Patient verbs (e.g., phone) and in Stimulus-Experiencer verbs (e.g., frighten). The usual bias in favor of the Agent or the Stimulus for causality can be reversed with certain verbs depending on their thematic structure. With verbs that have both an action and a psychological component, and the second argument can be the cause of the action (e.g., thank, praise, punish), speakers assign a different theta role to the second argument (Evocator instead of Patient, as evidenced by our non-linguist raters). This strengthens the argument in favor of a connection between the theta roles assigned to constituents and the implicit biases about cause and consequence observed in processing. The theta role of the patient is able to change the interpretational bias for causality usually found in favor of the Agent. 


\section{$\underline{\text { Reference Notes }}$}

1. Because French first names cannot always be translated, the English translation will mention "Masc." for a masculine first name and "Fem." for a female first name. 


\section{References}

Brown, R., \& Fish, D. (1983). The psychological causality implicit in language. Cognition, $\underline{14}$, 237-273.

Chesnet, D., Guillabert, F., \& Esperet, E. (1994). G-Studio: un logiciel pour l'étude en temps réel des paramètres en temps réel de la production écrite. L’Année Psychologique, 94, 283-294.

Crinean, M., \& Garnham, A. (2006). Implicit causality, implicit consequentiality and semantic roles. Language and Cognitive Processes, 21, 636-648

Dowty, D. (1991). Thematic proto-roles and argument selection. Language, 67, 547-619.

Frege, G. (1994). On sense and reference. In R. Harnish (Ed.), Basic topics in the philosophy of language (pp. 142-160). Englewood Cliffs, N.J., Prentice-Hall. (Original work published 1892)

Garvey, C., \& Caramazza, A. (1974). Implicit causality in verbs. Linguistic Inquiry, $\underline{5}$, 469-464.

Grober, E.H,, Beardsley, W., \& Caramazza, A. (1978). Parallel function strategy in pronoun assignment. Cognition, $\underline{6}, 117-133$.

Guerry, M., Gimenes, M., Caplan, D., \& Rigalleau, F. (2006). How long does it take to find a cause ? An on-line investigation of implicit causality in sentence production. Quarterly Journal of Experimental Psychology, 59, 1535-1555.

Kehler, A. (2002). Coherence, reference, and the theory of grammar. Stanford, CA: CSLI Publications.

Lakoff, R. (1971). If's, and's, and but's about conjunction. In C.J. Fillmore \& D.T. Langendoen (Eds.), Studies in Linguistic Semantics. (pp. 114-149). New York: Reinhart and Winston.

Levin, B., \& Rappaport Hovav, M. (2005). Argument realization. Cambridge: Cambridge University Press.

McKoon, G., Greene, S.B., \& Ratcliff, R. (1993). Discourse models, pronoun resolution, and the implicit causality of verbs. Journal of Experimental Psychology: Learning, Memory, and Cognition, 19, 1040-1052. 
Pickering, M.J., \& Majid, A. (2007). What are implicit causality and consequentiality? Language and Cognitive Processes, 22, 780-788.

Rudolph, U., \& Försteling, F. (1997). The psychological causality implicit in verbs: A review. Psychological Bulletin, 121, 192-218.

Stevenson, R.J., Crawley, R.A., \& Kleinman, D. (1994). Thematic roles, focus and the representation of events. Language and Cognitive Processes, 9 , 519-548.

Stewart, A.J., Pickering, M.J., \& Sanford, A.J. (1998). Implicit consequentiality. In Proceedings of the Twentieth Annual Conference of the Cognitive Science Society (pp. 1031-1036).

Mawah, N.J.: Lawrence Erlbaum Associates, Inc. 
Appendix 1: Complete list of the verbs used in the experiments. Bias corresponds to implicit causality bias (NP : noun phrase).

\begin{tabular}{|c|c|c|c|}
\hline \multicolumn{2}{|c|}{ Psychological Verbs } & \multicolumn{2}{|c|}{ Action Verbs } \\
\hline NP1 biasing verbs & $\underline{\text { NP2 biasing verbs }}$ & $\underline{\text { NP1 biasing verbs }}$ & $\underline{\text { NP2 biasing verbs }}$ \\
\hline influencer (influence) & juger (judge) & désobéir (disobey) & protéger (protect) \\
\hline troubler (trouble) & mépriser (scorn) & importuner (importune) & engueuler (blame) \\
\hline mécontenter (displease) & se méfier de (mistrust) & supplier (implore) & secourir (assist) \\
\hline effrayer (frighten) & redouter (dread) & téléphoner (phone) & consoler (console) \\
\hline charmer (charm) & respecter (respect) & persuader (persuade) & aider (help) \\
\hline indigner (outrage) & apprécier (appreciate) & convaincre (convince) & punir (punish) \\
\hline irriter (irritate) & craindre (fear) & déranger (to disturb) & embaucher (hire) \\
\hline énerver (annoy) & aimer (love) & s'excuser (apologize) & complimenter(congratulate) \\
\hline
\end{tabular}


Figure 1 : Tablet surface (The active zone in grey is the part of the tablet surface which can detect the position of the stylus). The "departure square" is in black color. The second square (in white coulour) was the zone of the tablet where the participant posed the pen after reading the fragment.

(Black triangles represent four supports maintaining the position of the sheet).

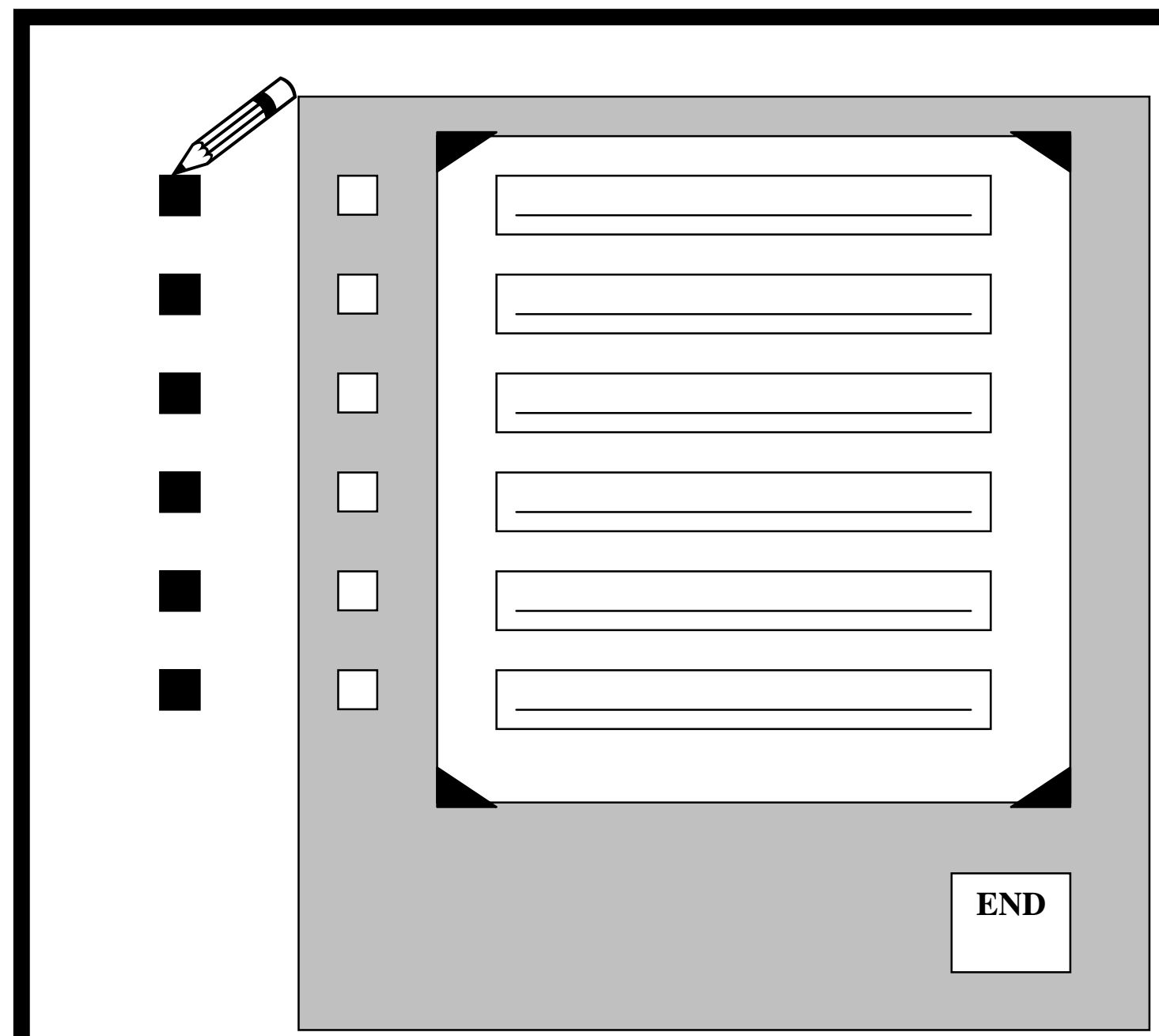


Connectives and argument selection

Table 1. Properties of the verbs used in the Experiments. Standard deviations using verbs as random variable are indicated between brackets.

\begin{tabular}{|c|c|c|c|}
\hline Continuation & Role & udgment & Reactor Judgment \\
\hline Task & Task & & Task \\
\hline Causal bias & NP1 Agent & NP1 Patient & $\begin{array}{l}\text { NP1Reactor } \\
(\operatorname{Max}=4)\end{array}$ \\
\hline
\end{tabular}

Agent-Patient verbs

$\begin{array}{lllll}\text { NP1 causal bias } & \begin{array}{l}80.5 \% \\ (9.0)\end{array} & \begin{array}{l}97.3 \% \\ (6.2)\end{array} & \begin{array}{l}4.5 \% \\ (6.5)\end{array} & \begin{array}{l}2.05 \\ \text { NP2 causal bias }\end{array} \\ & \begin{array}{l}81.0 \% \\ (4.2)\end{array} & 98.6 \% & 0.4 \% & 3.3 \\ & (1.8) & (1.3) & (0.5)\end{array}$

Psychological verbs
Causal biais
NP1 StimulusNP1 Experiencer

$\begin{array}{llll}\text { NP1 causal bias } & 82.4 \% & 93.7 \% & 3.6 \% \\ & (9.4) & (7.1) & (1.9) \\ \text { NP2 causal bias } & \begin{array}{l}81.9 \% \\ (11.7)\end{array} & 6.7 \% & 93.3 \% \\ & & (6.2) & (9.4)\end{array}$

Note : For the role judgment task, participants had to select which NP (NP1 or NP2) had a specific role for each verb. So NP2 scores were complementary to the reported scores for NP1. For the reactor judgment task, participants had to assign a note between 0 and 4 according to the level at which NP1 reacted to the behavior of NP2. 
Table 2. Mean percentages of references to NP1 in the continuations with the connective "so" and "but" in the Experiment 1. The first column reports the mean percentages obtained for the connective "because" in the pre-selection of verbal material. Standard deviations are given in parentheses. The $\underline{t}$ values testing relative to random proportion are given by participants $\left(\mathrm{t}_{1}\right)$ and by items $\left(\mathrm{t}_{2}\right)$.

$\begin{array}{ccc} & \text { Connective } \\ \text { Because } & \text { So } & \text { But }\end{array}$

Verbal causal bias NP1

overall mean

Agent-Patient

$80.5 \%$

$25.0 \%$

(14.3)

$30.5 \%$

$45.3 \%$

$\mathrm{t}_{1}=10.7, \mathrm{p}<.01$

$\mathrm{t}_{1}=-9.1, \mathrm{p}<.01$

$\mathrm{t}_{1}=-6.8, \mathrm{p}<.01$

$\mathrm{t}_{2}=9.6, \mathrm{p}<.01$

$\mathrm{t}_{2}=-4.2, \mathrm{p}<.01$

$\mathrm{t}_{2}=-2.9, \mathrm{p}<.05$

Stimulus-Experiencer $82.4 \%$

$22.2 \%$

(15.6)

$30.5 \%$

$45.0 \%$

(15.2)

$\mathrm{t}_{1}=11.1, \mathrm{p}<.01$

$\mathrm{t}_{1}=-9.2, \mathrm{p}<.01$

$\mathrm{t}_{1}=-6.6, \mathrm{p}<.01$

$\mathrm{t}_{2}=9.7, \mathrm{p}<.01$

$\mathrm{t}_{2}=-8.3, \mathrm{p}<.01$

$\mathrm{t}_{2}=-4.9, \mathrm{p}<.01$

Mean $81.4 \%$

$23.6 \%$

$30.5 \%$

Verbal causal bias NP2

overall mean

Agent-Evocator

$19.0 \%$

(12.2)

$17.6 \%$

(16.3)

$25.5 \%$

(13.6)

$\mathrm{t}_{1}=-13.2, \mathrm{p}<.01$

$\mathrm{t}_{1}=-10.2, \mathrm{p}<.01$

$\mathrm{t}_{1}=-9.3, \mathrm{p}<.01$

$\mathrm{t}_{2}=-21, \mathrm{p}<.01$

$\mathrm{t}_{2}=-8.9, \mathrm{p}<.01$

$\mathrm{t}_{2}=-7.1, \mathrm{p}<.01$

Experiencer-Stimulus $\quad 18.0 \%$

(15.2)

$56.0 \%$

$54.2 \%$

$42.7 \%$

$$
\begin{aligned}
& \mathrm{t}_{1}=-10.8, \mathrm{p}<.01 \\
& \mathrm{t}_{2}=-7.6, \mathrm{p}<.01
\end{aligned}
$$

Mean 18.5\%

overall mean

$50.0 \%$
(17.1)

$\mathrm{t}_{1}=1.8, \mathrm{p}>.05$

(14.3)

$\mathrm{t}_{2}=-0.6, \mathrm{p}>.05$

$36.8 \%$

$\mathrm{t}_{1}=1.5, \mathrm{p}>.05$

$\mathrm{t}_{2}=-0.9, \mathrm{p}>.05$

$39.8 \%$

$35.1 \%$ 
Table 3. Mean planning times (ms) in Experiment 2 with the connective "but" according to the verbs and the name referred by the pronoun. Standard deviations are given in parentheses.

Pronominal Referent
NP1

Verbal causal bias NP1

$\begin{array}{llll}\text { Agent-Patient } & \begin{array}{l}5,133 \\ (2,518)\end{array} & 3,972 & 4,552 \\ & & (2,024) & \\ \text { Stimulus-Experiencer } & 6,035 & 4,736 & 5,385 \\ & (3,053) & (2,748) & \\ \text { Mean } & 5,584 & 4,354 & \end{array}$

Verbal causal bias NP2

\begin{tabular}{llll} 
Agent-Evocator & 5,615 & 4,230 & 4,922 \\
& $(2,418)$ & $(2,294)$ & \\
Experiencer-Stimulus & $\begin{array}{l}4,846 \\
(2,396)\end{array}$ & 6,328 & 5,587 \\
& & $(2,870)$ & \\
Mean & 5,230 & 5,279 & \\
& & & \\
\cline { 2 - 3 } Overall Mean 5,407 & 4,817
\end{tabular}


Table 4. Mean percentages of completions referring to a potential consequence in Experiment 2. Standard deviations are given in parentheses. The $\underline{t}$ values testing relative to random proportion are given by participants $\left(\mathrm{t}_{1}\right)$ and by items $\left(\mathrm{t}_{2}\right)$.

Pronominal Referent

$$
\text { NP1 }
$$

Verbal causal bias NP1
Agent-Patient
$33.7 \%$
(19.1)
$75.6 \%$
(19.2)
$\mathrm{t}_{1}=-3.8, \mathrm{p}>.05$
$\mathrm{t}_{2}=-3.1, \mathrm{p}<.01$
$\mathrm{t}_{1}=5.9, \mathrm{p}<.01$
$\mathrm{t}_{2}=4.4, \mathrm{p}<.01$
Stimulus-Experiencer
$34.3 \%$
$(23.2)$
$71.8 \%$
(19.8)
$\mathrm{t}_{1}=-3, \mathrm{p}<.05$
$\mathrm{t}_{2}=-3, \mathrm{p}<.05$
Mean $\quad 34 \%$
$\mathrm{t}_{1}=4.9, \mathrm{p}<.01$
$\mathrm{t}_{2}=3.7, \mathrm{p}<.01$
$73.7 \%$

Overall Mean

$54.6 \%$

$53 \%$

$68.1 \%$

(22.0)

(23.1)

$\mathrm{t}_{1}=3.6, \mathrm{p}<.01$

$\mathrm{t}_{2}=4.2, \mathrm{p}<.01$

$\mathrm{t}_{2}=-3.4, \mathrm{p}<.01$

$31.2 \%$

(22.7)

(18.1)

$\mathrm{t}_{1}=-3.6, \mathrm{p}>.05$

$\mathrm{t}_{2}=-3.6, \mathrm{p}<.01$

$\mathrm{t}_{1}=2.7, \mathrm{p}<.02$

$\mathrm{t}_{2}=2.1, \mathrm{p}=.07$

Mean

$52.4 \%$

$49.6 \%$
$55.9 \%$

$46.2 \%$

Overall Mean

$43.2 \%$

$61.6 \%$ 
Table 5. Examples of negative continuation (a), and affirmative continuation (b) where the pronoun referred to the Experiencer or to the Patient for each type of verb in Experiment 2. The examples marked with (a') and (b') are the resulting transformed sentences.

Agent-Patient verb with a causal bias in favor of NP1:

Antoine a supplié Valérie [Masc. implored Fem.]

(a) mais elle n'a pas dit "oui" .[ but she did not say "yes"]

(a') donc elle a dit "oui".[ so she said "yes"]

(b) mais elle est restée sur ses positions. [but she stood her ground]

(b') donc elle n'est pas restée sur ses positions. [so she did not stand her ground]

Stimulus-Experiencer verb with a causal bias in favor of NP1:

Richard a mécontenté Justine [Masc. displeased Fem.]

(a) mais elle ne s'est pas fâchée. [but she did not get angry]

(a') donc elle s'est fâchée. [so she got angry]

(b) mais elle lui laissera une nouvelle chance.[but she will give him a new chance]

(b') donc elle ne lui laissera pas une nouvelle chance. [so she will not give him a new chance]

Agent-Evocator (or Agent-Patient) verb with a causal bias in favour of NP2:

Bernard a protégé Martine [Masc. protected Fem.]

(a) mais elle ne l'a pas remercié. [but she did not thank him]

(a') donc elle l'a remercié. [so she thanked him]

(b) mais elle est tombée dans le trou. [but she fell into the hole.]

(b') donc elle n'est pas tombée dans le trou. [so she did not fell into the hole.]

Experiencer-Stimulus verb with a causal bias in favour of NP2:

Hélène a apprécié Julien [Fem. appreciated Masc.]

(a) mais elle ne l'a pas invité pour sa fête. [but she did not invite him at her party]

(a') donc elle l'a invité pour sa fête. [so invited him at her party]

(b) mais elle est déçue par son comportement. [but she is disappointed by his behaviour]

(b') donc elle n'est pas déçue par son comportement. [so she is not disappointed by his behaviour] 
Table 6. Number (and corresponding percentages) of transformed continuations corresponding to a negation of a plausible consequence in Experiment 2. The Chi square $\left(\chi^{2}\right)$ value comparing with chance is reported for each condition. For each pronominal referent, the first column reports the total number of consequence continuations.

\begin{tabular}{|c|c|c|c|}
\hline \multirow{4}{*}{$\begin{array}{l}\text { All } \\
\text { Consequences }\end{array}$} & \multicolumn{2}{|c|}{ Pronominal Referent } & \multirow[b]{3}{*}{ Plausible } \\
\hline & & NP2 & \\
\hline & Plausible & All & \\
\hline & $\begin{array}{l}\text { Transformed } \\
\text { Consequences }\end{array}$ & Consequences & $\begin{array}{l}\text { Transformed } \\
\text { Consequences }\end{array}$ \\
\hline
\end{tabular}

Verbal causal bias NP1

$\begin{array}{rrrlll}\text { Agent-Patient } & \mathrm{N} & 54 & 46 & 121 & 107 \\ & \% & & 85.1 \% & & 88.4 \% \\ & \chi^{2} & & 26.7(\mathrm{p}<.01) & & 71.4(\mathrm{p}<.01) \\ \text { Stimul.-Exper. } & \mathrm{N} & 55 & 44 & & \\ \% & & 80.0 \% & 115 & 104 \\ \chi^{2} & & 19.8(\mathrm{p}<.01) & & 90.4 \% \\ & & & & 75.2(\mathrm{p}<.01)\end{array}$

Verbal causal bias NP2

\begin{tabular}{rlllll} 
Agent-Evocator & $\mathrm{N}$ & 70 & 58 & 108 & 101 \\
& $\%$ & & $82.8 \%$ & & $93.5 \%$ \\
& $\chi^{2}$ & & $30.2(\mathrm{p}<.01)$ & & $81.8(\mathrm{p}<.01)$ \\
Exper.-Stimul. & $\mathrm{N}$ & 98 & 88 & \multirow{2}{*}{50} & 43 \\
& $\%$ & & $89.7 \%$ & & $86 \%$ \\
& $\chi^{2}$ & & $62.1(\mathrm{p}<.01)$ & & $25.9(\mathrm{p}<.01)$
\end{tabular}


Table 7. Examples of continuations where the pronoun referred to the Agent or to the Stimulus (a), with the negation test on the consequence (a'), given for each type of verb in Experiment 2.

Agent-Patient verb with a causal bias in favor of NP1:

Etienne a désobéi à Josiane [Masc. disobeyed Fem.]

(a) mais il a été puni .[ but he was punished]

(a') ? donc il n'a pas été puni.[ so he was not punished]

Stimulus-Experiencer verb with a causal bias in favor of NP1:

Justine a mécontenté Richard [Fem. displeased Masc.]

(a) mais elle a regretté ses paroles. [but she regretted her words]

(a') ? donc elle n'a pas regretté ses paroles. [so she did not regret her words]

Agent-Evocator (or Agent-Patient) verb with a causal bias in favour of NP2:

Martine a protégé Bernard [Fem. protected Masc.]

(a) mais elle a été blessée. [but she was hurt]

(a') ? donc elle n'a pas été blessée. [so she was not hurt]

Experiencer-Stimulus verb with a causal bias in favour of NP2:

Grégory a méprisé Aurélie [Masc. scorned Fem.]

(a) mais elle s'est fâchée. [but she got angry]

(a') ? donc elle ne s'est pas fâchée. [so she did not get angry] 